\title{
Penerapan Model Pembelajaran Blended-Problem Solving melalui Aplikasi Moodle untuk Meningkatkan Kemampuan Berpikir Kreatif Kelas XI IPA 4 SMA N 3 Surakata Tahun Pelajaran 2012/2013
}

Implementation of Blended-Problem Solving Through Moodle Application for Increasing Creative Thinking Ability of XI IPA 4 Class SMA N 3 Surakarta in Academic Year Of 2012/2013

\author{
Vebriana Irandasari K W ${ }^{\mathbf{a}}$, Riezky Maya $\mathbf{P}^{\mathbf{b}}$, Suciati ${ }^{\mathrm{c}}$ \\ ${ }^{a}$ Pendidikan Biologi FKIP UNS, Email: iyrandhasarrii@yahoo.com \\ ${ }^{\mathrm{b}}$ Pendidikan Biologi FKIP UNS, Email: riezkymp@gmail.com \\ ${ }^{\mathrm{c}}$ Pendidikan Biologi FKIP UNS, Email: suciati.sudarisman@yahoo.com
}

Diterima 4 Juli 2013, disetujui 2 Desember 2013

\begin{abstract}
This study is aimed to improve creative thinking ability of XI IPA4 class of SMA N 3 Surakarta through the implementation of Blended-Problem Solving through moodle application. This research was a classroom action research held in 3 cycles, each cycle includes four stages: planning, action, observation, and reflection. The subject of this research is the students of XI IPA4 class at SMA N 3 Surakarta in academic year of 2012/2013. The data is obtained through the test (essay test) and non-test (observation, interviews and questionnaires). The data is analyzed with descriptive analytical techniques and validated by triangulation techniques. The results showed that students creative thinking ability is increased in Pre-cycle, Cycle I, Cycle II and Cycle III. Creative thinking consist of four aspects are fluency, flexibility, originality and elaboration. Fluency aspect has increased was $52,5 \%$, flexibility aspect was $54,17 \%$, the originality aspect was $61,66 \%$ and elaboration aspect was $55,83 \%$. The research conclouded that the implementation of Blended-Problem Solving through moodle application can improve creative thinking ability of XI IPA4 class at SMA N 3 Surakarta in academic year of 2012/2013.
\end{abstract}

Key Words: Blended-Problem Solving, Moodle, Creative Thinking

\section{Pendahuluan}

Era Globalisasi saat ini tidak hanya berdampak bagi kehidupan ekonomi tetapi juga pendidikan. Pendidikan tidak hanya dituntut untuk dapat mengimbangi kemajuan Ilmu Pengetahuan dan Teknologi tetapi yang terpenting sumber daya manusia juga dapat berkembang searah dengan kemajuan perkembangan tersebut. Pendidikan adalah sarana untuk mengimbangi kemajuan perkembangan ilmu pengetahuan dan teknologi dengan berbagai perubahan cara pembelajaran sesuai dengan kondisi dan tujuan pembelajaran yang akan dicapai sehingga tercipta generasi bangsa yang berkualitas dan berdaya saing tinggi. Menyikapi persaingan global sistem pendidikan Indonesia diarahkan seperti yang disebutkan dalam Standar Isi Permendiknas (BNSP, 2006) bahwa peningkatan mutu pendidikan diarahkan untuk meningkatkan kualitas manusia Indonesia seutuhnya melalui olah hati, olah pikir, olahrasa dan olahraga agar 
memiliki daya saing dalam menghadapi tantangan global.

Biologi merupakan ilmu yang berhubungan segala sesuatunya dengan Alam Pembelajaran Sains dituntut untuk dapat meningkatkan peserta didik dengan berbagai ketrampilan dan kecakapan berpikir kreatif, inovatif, kritis dalam memecahkan masalah, komunikasi, ICT literacy dan kepemimpinan (National Science Teacher Association : 2006).

Pembelajaran sains di Sekolah Menengah Atas khususnya biologi harus berkembang seiring dengan dunia pendidikan yang terus melaju mengikuti perkembangan zaman. Berbagai upaya diperlukan untuk dapat mengimbangi perkembangan zaman yang terus melesat salah satunya adalah penyampaian pembelajaran dengan menggunakan IT (Information Technology) atau lebih dikenal dengan pembelajaran berbasis komputer.

Perkembangan teknologi yang semakin maju mendukung pembelajaran yang semakin menarik dengan berbagai media yang bisa digunakan seperti moodle, laboratorium virtual, macromedia flash dan sebagainya. Pembelajaran biologi tidak hanya dapat disampaikan dengan cara klasik yang konvensional tetapi dapat menggunakan berbagai media teknologi yang berkembang saat ini yang ada disekitar kita. Pembelajaran biologi juga harus diajarkan berdasarkan hakekat pembelajaran sains yang mencakup ranah kognitif (minds on), ranah afektif (hearts on) dan psikomotor (hands on ) (Rustaman, 2011).

Berdasarkan hasil observasi terhadap proses pembelajaran Biologi di kelas XI IPA 4 Tahun Pelajaran 2012/2013 didapatkan bahwa siswa masih kurang dalam menyampaikan pertanyaan mengenai materi yang diajarkan, kemudian beberapa ada yang tidak memperhatikan penjelasan dari guru dan juga ada beberapa siswa yang mengantuk. Siswa hanya terbatas pada buku paket sebagai sumber belajar. Kemampuan dalam menjawab pertanyaan dari guru masih terbilang monoton dengan kemampuan akademis siswa yang terbilang bagus. Hal ini dikarenakan sumber belajar siswa yang hanya terbatas pada buku sehingga siswa kurang mampu mengemukakan berbagai alternatif jawaban dengan berbagai sudut pandang dan terbilang baru, serta merinci jawaban tersebut. Hal ini mengindikasikan bahwa kemampuan berpikir kreatifnya masih rendah.

Perbaikan model pembelajaran pada kelas XI IPA 4 SMA N 3 Surakarta diperlukan guna meningkatkan kemampuan berpikir kreatif siswa. Model pembelajaran yang dianggap dapat meningkatkan kemampuan berpikir 
kreatif siswa sekaligus membekali siswa dalam penguasaan TIK yaitu model Blended-Problem Solving. BlendedProblem Solving merupakan perpaduan antara model pembelajaran blended learning dan problem solving. Model pembelajaran yang mengintegrasikan antara pembelajaran tatap muka dan pembelajaran berbasis web dikombinasikan dengan pemecahan permasalahan yang diberikan kepada siswa sehingga kemampuan berpikir tingkat tinggi siswa dapat ditingkatkan khususnya kemampuan berpikir kreatif siswa. Pemecahan masalah (problem solving) yang disajikan dapat menstimulasi kemampuan berpikir tingkat tinggi siswa sehingga dengan adanya model ini siswa tidak hanya dapat terampil dalam pemanfaatan media pembelajaran yang berkembang tetapi juga dapat meningkatkan kemampuan berpikir tingkat tinggi siswa khususnya kemampuan berpikir kreatif.

Penggunaan model tersebut mempunyai kelebihan diantaranya guru dan siswa dapat melakukan kegiatan diskusi diluar jam tatap muka. Guru dapat menambahkan materi pengayaan melalui fasilitas internet kemudian kegiatan diskusi dapat dikontrol dengan baik oleh guru.

Moodle adalah salah satu alternatif software yang dapat digunakan oleh guru sebagai sarana diskusi di dunia maya dengan berbagai aktivitas pembelajaran yang dapat didukung oleh moodle diantaranya assignment, chat, forum, quiz, survey (Amirah, 2012). Adanya kombinasi dari Blended-Problem Solving dengan aplikasi moodle, siswa dapat dengan leluasa berdiskusi antar siswa maupun guru diluar jam tatap muka. Pengkombinasian tersebut diharapkan dapat meningkatkan kemampuan berpikir kreatif siswa.

\section{Metode Penelitian}

Penelitian ini dilaksanakan pada semester genap Tahun Pelajaran 2012/2013 di kelas XI IPA 4 SMA N 3 Surakarta yang beralamat di J1. Prof WZ Johanes 58, Surakarta. Secara garis besar pelaksanaannya dibagi menjadi tiga tahap, yaitu: tahap persiapan, penelitian dan penyelesaian. Penelitian Tindakan Kelas ini dilakukan dalam tiga siklus pada tanggal 23 April 2013 sampai 8 Mei 2013 dengan subjek penelitian yaitu siswa kelas XI IPA 4 SMA N 3 Surakarta Tahun Pelajaran 2012/2013, yang berjumlah 30 siswa.

Sebelum dilaksanakan penelitian dilakukan tes awal sebagai dasar kemampuan berpikir analitis siswa. Setelah dilakukan tindakan prasiklus maka diadakan tes pada setiap akhir siklus yang mengukur kemampuan 
berpikir kreatif siswa terhadap materi yang diajarkan.

Pengumpulan data menggunakan teknik tes dengan soal uraian dan teknik non tes dengan pengamatan atau observasi, wawancara dan dokumentasi yang dilakukan saat proses pembelajaran dan setelah akhir siklus. Teknik yang digunakan untuk memeriksa validitas data yang digunakan dalam penelitian ini adalah triangulasi. Triangulasi adalah teknik pengumpulan data yang bersifat menggabungkan dari berbagai teknik pengumpulan data dan sumber data yang telah ada.

Langkah-langkah operasional penelitian pada tiap siklus ada empat, yaitu 1) perencanaan: berdasarkan hasil identifikasi masalah dari kegiatan observasi yang telah dilakukan sebelumnya, alternatif pemecahan masalah yang diajukan adalah dengan penerapan model pembelajaran BlendedProblem Solving untuk meningkatkan kemampuan berpikir kreatif siswa pada pokok bahasan sistem reproduksi. Pada tahap ini dilakukan penyusunan skenario pembelajaran penyusunan silabus dan rencana pengajaran. Instrumen yang digunakan dalam penelitian juga disiapkan seperti tes evaluasi, tes kemampuan berpikir analitis, LKS, lembar observasi, angket serta pedoman wawancara; 2) pelaksanaan: tindakan yang telah direncanakan diimplementasikan dalam bentuk penerapan model pembelajaran Blended-Problem Solving. Pelaksanaan tindakan diwujudkan dalam Rencana Pelaksanaan Pembelajaran (RPP); 3) Observasi: observasi dilakukan selama berlangsungnya proses pembelajaran. Observasi berupa kegiatan pemantauan, pencatatatan serta pendokumentasian segala kegiatan selama pembelajaran. Observasi juga dilakukan pada keterlaksanaan pembelajaran model pembelajaran Blended-Problem Solving; dan 4) refleksi: pada tahap ini dilakukan analisis proses dan dampak dari pelaksanaan tindakan. Hasil analisis pada tahap refleksi berupa kelebihan, kelemahan ataupun hambatan dalam pelaksanaan tindakan dasar perencanaan kegiatan pada siklus sebelumnya.

Indikator kinerja dalam penelitian ini meliputi empat aspek kemampuan berpikir kreatif. Target pencapaian pada penelitian dengan model pembelajaran Blended-Problem Solving sebesar $\geq 20 \%$ untuk tiap aspek.

\section{Hasil Dan Pembahasan}

Prasiklus dilakukan dengan memberikan instrumen tes dengan materi ekskresi untuk mengetahui kemampuan awal siswa. Hasil test untuk setiap aspek kemampuan berpikir kreatif adalah fluency sebesar $34,17 \%$ kemudian flexibility 
sebesar 27,5\%, originality sebesar $11,67 \%$ dan elaboration sebesar 17,5\%. Hasil dari test prasiklus ini dijadikan sebagai patokan awal dalam peningkatan kemampuan berpikir kreatif melalui penerapan Blended-Problem Solving.

Siklus I diperoleh hasil bahwa tiap aspek kemampuan berpikir kreatif siswa meningkat dibandingkan dengan hasil test dari Prasiklus. Aspek fluency (kelancaran dalam berpikir) sebesar $72,50 \%$, flexibility (berpikir luwes) sebesar $33,33 \%$, originality (orisinalitas) sebesar 55,83\%, dan elaboration (menguraikan jawaban) sebesar 43,33\%.

Siklus II diperoleh hasil untuk setiap aspek kemampuan berpikir kreatif meningkat jika dibandingkan dengan hasil test pada Siklus I. Fluency (kelancaran dalam berpikir) sebesar $77,50 \%$, flexibility (berpikir luwes) sebesar $57,50 \%$, originality (orisinalitas) sebesar $65 \%$ dan elaboration (menguraikan jawaban) sebesar 56,67\%. Perbandingan peningkatan kemampuan berpikir kreatif siswa kelas XI IPA 4 dari Prasiklus hingga Siklus III disajikan pada Gambar 1.

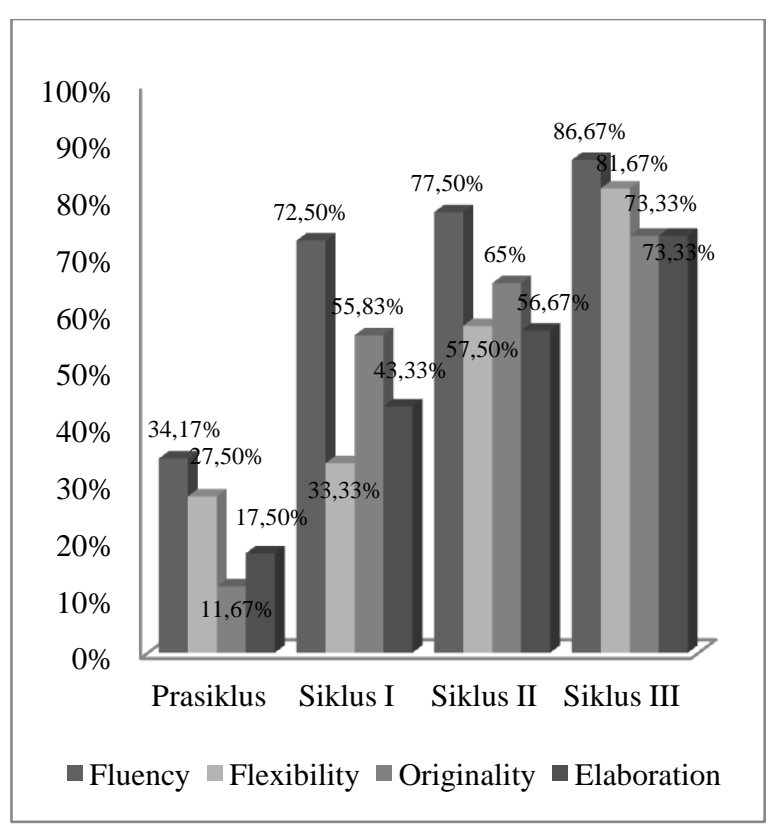

Gambar 1. Grafik Peningkatan Kemampuan Berpikir Kreatif Siswa pada Prasiklus, Siklus I, Siklus II dan Siklus III

Siklus III diperoleh hasil bahwa peningkatan tiap aspek kemampuan berpikir kreatif siswa sudah memenuhi target penelitian sebesar $20 \%$. Hasil test pada Siklus III menunjukkan peningkatann yang lebih baik jika dibandingkan dengan Prasiklus, Siklus I dan Siklus II. Fluency (kelancaran dalam berpikir) sebesar 86,67\%, flexibility (berpikir luwes) sebesar 81,67\%, originality (orisinalitas) sebesar 73,33\% dan elaboration (menguraikan jawaban) sebesar $73,33 \%$.

\section{Pembelajaran Blended-Problem} Solving berlangsung melalui dua tahap yaitu pembelajaran online dan pembelajaran tatap muka. Moodle digunakan sebagai sarana diskusi online 
bagi siswa, dan guru dapat mengontrol didalamnya. Guru memberikan wacana (kasus) yang diunggah pada moodle kemudian siswa berdiskusi dengan fitur forum untuk menyelesaikan permasalahan yang diberikan.

Peningkatan aspek kemampuan berpikir kreatif terlihat setelah BlendedProblem Solving diimplementasikan kedalam pembelajaran biologi kelas XI IPA 4. Siswa dilatih untuk memecahkan masalah yang telah diunggah oleh guru pada moodle. Permasalahan yang menyangkut pokok bahasan sistem reproduksi dekat dengan kehidupan sehari-hari, seperti kelainan dan penyakit yang terjadi pada organ reproduksi. Sehingga memungkinkan siswa untuk dapat mengaplikasikannya dalam kehidupan sehari-hari.

Kemampuan dalam memcahkan masalah ini berkaitan dengan kemampuan berpikir tingkat tinggi terutama berpikir kreatif yang meliputi. Fluency (kelancaran) ,aspek ini terlihat ketika siswa berdiskusi memecahkan masalah dan menyebutkan berbagai alternatif rumusan masalah yang diberikan. Melalui forum moodle terlihat aktivitas siswa mengemukakan berbagai pendapat mereka mengenai alternatif rumusan dan pemecahan masalah mengenai wacana yang diberikan.
Fluency (kelancaran) meupakan aspek pertama yang mengalami peningkatan cukup berarti dari prasiklus hingga Siklus I dan mengalami peningkatan hingga Siklus III. Pada Siklus I siswa terlihat antusias dalam berdiskusi dalam forum moodle, meskipun pada awalnya mengalami kesulitan karena instruksi yang diberikan oleh guru kurang jelas. Tetapi siswa sudah mulai mengemukakan berbagai pendapatnya untuk menyelesaikan permasalahan yang diberikan. Pada Siklus II siswa sudah mulai lebih aktif dalam penggunaan media moodle dibandingkan siklus sebelumya. Instruksi yang diberikan oleh guru juga cukup jelas. Pada Siklus III mengalami peningkatan terlihat dari banyakknya komentar siswa mengenai alternatif rumusan dan penyelesaian masalah yang diberikan pada forum moodle.

Flexibility (ketrampilan berpikir luwes) merupakan aspek dari siswa agar dapat memandang suatu permasalahan dengan sudut pandang yang berbedabeda, sehingga menghasilkan berbagai jawaban yang bervariasi. Pada Siklus I ini siswa belum terbiasa dalam mencari berbagai sumber mengenai permasalahan yang diberikan. Siklus II siswa sudah mulai terbiasa dengan diskusi online dan mencari berbagai alternatif jawaban berdasarkan sumber masing-masing dan 
dibagikan pada forum moodle untuk setiap anggota kelompok. Pada Siklus III mengalami peningkatan, siswa sudah terbiasa dengan diskusi online dan memberikan alternatif penyelesaian permasalahan berdasarkan sudut pandang masing-masing dengan berbagai referensi yang didapatkan. Jika dikaitkan dengan pembelajaran online yang ada didalam pembelajaran Blended-Problem Solving dapat merangsang kemampuan berpikir luwes dengan berbagai sumber yang didapat, sehingga mampu merangsang siswa untuk menganalisis dengan berbagai sudut pandang yang berbeda.

Aspek originality (keaslian) merupakan aspek dari siswa agar dapat menghasilkan gagasan-gagasan baru atas penyelesaian masalah dari hasil pemikiran sendiri. Aspek ini terlihat dari penyelesaian siswa mengenai permasalahan yang diberikan bukan hasil plagiat dari sumber yang mereka dapatkan. Pada Siklus I aspek ini belum begitu terlihat karena siswa kebanyakan hanya mengcopy dari sumber yang mereka dapatkan. Pada Siklus II mengenai materi fertilisasi dan siklus menstruasi siswa sudah mulai menambahkan pendapat mereka sendiri mengenai permasalahan yang diberikan. Pada Siklus III mengalami peningkatan dengan pengembangan hasil pemikiran mereka sendiri terhadap permasalahan yang diberikan mengenai hormon dan kelainan yang terjadi pada organ reproduksi pria dan wanita.

Kemampuan menjabarkan atau memperinci suatu solusi mengenai permasalahan merupakan salah satu aspek kemampuan berpikir kreatif yaitu elaboration. Penemuan solusi (gagasan) mengenai permasalahan yang diberikan tidak terlepas dari penjabaran atas solusi tersebut.. Pada Siklus I aspek elaboration belum begitu nampak terlihat dari jawaban penyelesaian yang diberikan. Kemudian presentasi ketika pembelajaran tatap muka siswa juga kurang maksimal, karena keterbatasan waktu sehingga penjabaran hasil diskusi kurang optimal serta kurangnya motivasi siswa, ketika guru memberikan permasalahan baru pada akhir pembelajaran sebagai pengayaan. Pada Siklus II mengenai fertilisasi dan siklus menstruasi aspek elaboration sudah mulai terlihat dari jawaban penyelesaian yang diberikan mulai dikembangkan. Pada Siklus III mengalami peningkatan penjabaran penyelesaian yang diberikan.

Berdasarkan hasil tes kemampuan berpikir kreatif siswa terjadi peningkatan yang berbeda-beda untuk tiap aspek dalam setiap Siklus. Model pembelajaran Blended-Problem Solving mampu meningkatkan kemampuan berpikir kreatif siswa. Hasil capaian tes 
kemampuan berpikir kreatif siswa pada Prasiklus, Siklus I, Siklus II dan Siklus III.

Aktivitas penggunaan moodle mendukung bagi keterlaksanaan pembelajaran Blended-Problem Solving terutama pembelajaran online. Diskusi kelompok yang ada pada forum moodle akan merangsang kemampuan berpikir siswa dalam memecahkan permasalahan yang diberikan terutama kemampuan berpikir divergen (kreatif) dalam mencari penyelesaian. Hal ini diperkuat dengan pendapat Turkle (dalam Wheeler, 2002) yang menyatakan bahwa kreativitas dalam interaksi sosial online meliputi penciptaan dan penggunaan avatar pada chat room kemudian ekspresi diri melalui penggunaan komunikasi berbasis teks dan pendapat pada lingkungan elektronik

\section{Simpulan}

Berdasarkan hasil penelitian dapat disimpulkan bahwa penerapan model pembelajaran Blended-Problem Solving melalui aplikasi moodle dapat meningkatkan kemampuan berpikir kreatif kelas XI IPA 4 SMA $\quad$ N 3 Surakata.

\section{Daftar Pustaka}

Akkoyunlu, B., \& Soylu, M. Y. (2008). AStudy of Student's Perceptions in a Blended Learning Environment Based on Different Learning Styles. Educa- tional Technology \& Society, 11 (1), 183-193

AL-Hunaiyyan, A. (2008). Blended ELearning Design: Discussion of Cultural Issues. International Journal of Cyber Society and Education Vol. 1, No. 1, March 2008 , 17-32

Ambarjaya, B. S. (2008). Model-model Pembelajaran Kreatif. Bandung: Tinta Emas Publishing

Amiroh. (2012). Membangun E-Learning dengan Learning Management System. Jakarta : Genta Group Production

Arnyana, I. B. P. (2006). Pengaruh Penerapan Strategi Pembelajaran Inovatif Pada Pelajaran Biologi Terhadap Kemampuan Berpikir Kreatif Siswa SMA. Jurnal Pendidikan dan Pengajaran IKIP Negeri Singaraja. No.3 tahun XXXIX Juli 2006, 496515

Arikunto, S. (2010). Prosedur Penelitian: Suatu Pendekatan Praktik. Jakarta: Rineka Cipta

Aunurrahman. (2009). Belajar dan Pembelajaran. Bandung: Alfabeta

BNSP. (2006). Standar Isi Untuk Satuan Pendidikan Dasar dan Menengah. http://litbang.kemdikbud.go.id. 20/3/2012

Dahar, R.W. (2011). Teori-Teori Belajar dan Pembelajaran. Jakarta: Erlangga

Dimyati \& Mudjiono. (2002). Belajar dan Pembelajaran. Jakarta: PT Rineka Cipta

Faisal, A (2011). Upaya Peningkatan Keaktifan Siswa Melalui Implementasi Blended Learning Pada Pembelajaran Biologi Kelas XI SMAIT Nur Hidayah Kartasura. Skripsi Tidak Dipublikasikan, Universitas Sebelas Maret, Surakarta

Fasko, D. Jr. (2001). Education and Creativity. Creativity Research Journal, Vol. 13, Nos. 3 \& 4, 317-327

Gulo, W. (2002). Strategi BelajarMengajar. Jakarta: PT Gramedia Widiasarana Indonesia

Hamruni. (2012). Strategi Pembelajaran. Yogyakarta: Insan Madani 
Kusairi, S. (2011). Implementasi Blended Learning. Makalah disajikan pada Seminar Nasional Pengembangan Pembelajaran Berbasis Blended Learning. FMIPA Universitas Negeri Malang. Malang, 13 November 2011.

Hawadi, R.A., Wihardjo, R. S. D., dan Wiyono, M. (2001). Kreativitas. Jakarta: Grasindo

Liliawati, W. dan Erna, P. (2010). Efektivitas Pembelajaran Berbasis Masalah dalam Meningkatkan Keterampilan Berpikir Kreatif Siswa. Prosiding Seminar Nasional Fisika UPI Bandung, 423-431

Munandar, U. (2004). Pengembangan Kreativitas Anak Berbakat. Jakarta: PT Rineka Cipta. [electronic version] Journal of Educational Technology. 9(2), 87-96

Rini, A. S. I. (2012). Penerapan Pendekatan Problem Solving Melalui Model Pembelajaran Search, Solve, Create dan Share (SSCS) Disertai Hands On Activities untuk Meningkatkan Ketrampilan Berpikir Kreatif. Skripsi Tidak Dipublikasikan, Universitas Sebelas Maret, Surakarta.

Rustaman, N. Y. (2011). Pendidikan dan Penelitian Sains dalam Mengembangkan Ketrampilan Berpikir Tingkat Tinggi untuk Pembangunan Karakter. Makalah disajikan pada Seminar Nasional Biologi, Sains, Lingkungan, dan Pembelajarannya Menuju Pembangunan Karakter. Pendidikan Biologi FKIP UNS. Surakarta, 16 Juli 2011

Rustaman, N.Y. (2005). Strategi Belajar Mengajar Biologi. Bandung: UPI

Sana, F., Fenesi, B., \& Kim, J. A. (2011). A Case Study of the Introductory Psychology Blended Learning Model at McMaster University. The Canadian Journal for the Scholarship of Teaching and Learning

Sanjaya, W. (2008). Strategi Pembelajaran. Jakarta : Kencena
Siregar, E. (2010). Teori Belajar dan Pembelajaran. Bogor: Ghalia Indonesia

Slameto. (2010). Belajar dan FaktorFaktor yang Mempengaruhimya. Jakarta: PT. Rineka Cipta

Suciati, S. (2010). Membangun Karakter Peserta Didik Melalui Pembelajaran Biologi Berbasis Keterampilan Proses. Proceeding Seminar Nasional VII Pendidikan Biologi FKIP UNS Biologi, Sains, Lingkungan, dan Pembelajarannya, hlm. 237-243. Surakarta: FKIP Universitas Sebelas Maret Surakarta.

Sugiyono. (2011). Metode Penelitian Pendidikan Pendekatan Kuantitatif, Kualitatif, dan $R$ \& D. Bandung: Alfabeta

Rustini, T. (2008). Penerapan Model Problem Solving untuk Meningkatkan Pengembangan Potensi Berpikir Siswa Dalam Pembelajaran IPS di Sekolah Dasar. Jurnal Pendidikan Dasar Nomor: 10 - Oktober 2008

Trianto. (2007). Model-Model Pembelajaran Inovativ Berorientasi Konstruktivistik. Surabaya: Prestasi Pustaka.

Oliver, M., \& Trigwell, K. (2005). Can 'Blended Learning' Be Redeemed?. E-Learning Volume 2 Number 1,2005 .

Wenno, I. H. (2008). Strategi Belajar Mengajar Sains Berbasis Kontekstual Yogyakarta: Into Media.

Wheeler, S., Waite, S.J., \& Bromfield, C. (2002). Promoting creative thinking through the use of ICT. Journal of Computer Assisted Learning, 18, 367378

Wijayanti, F. N. (2012). Pengaruh Media Pembelajaran (Moodle) Budidaya Jamur Kuping Pada Pokok Bahasan Fungi Terhadap Kemampuan Kognitif Siswa Kelas X SMA Negei 3 Surakarta. Skripsi Tidak Dipublikasikan, Universitas Sebelas Maret, Surakarta.

Woodall, D., \& Hovis, S. (2010). Eight Phases of Workplace Learning: A 
Framework for Designing Blended Programs.

http://www.skillsoft.com/news/white_ papers.pdf. 10/1/2013

Yaman, M., \& Graf, D. (2010). Evaluation of an International Blended
Learning Cooperation Project in Biology Teacher Education. TOJET: The Turkish Online Journal of Educational Technology. 9(2), 87-96 